\title{
Benchmark dose analyses of multiple genetic toxicity endpoints permit robust, cross-tissue comparisons of MutaMouse responses to orally delivered benzo[a]pyrene
}

\author{
Alexandra S. Long ${ }^{1,2} \cdot$ John W. Wills ${ }^{1,2} \cdot$ Dorothy Krolak $^{1} \cdot$ Matthew Guo $^{1} \cdot$ Stephen D. Dertinger ${ }^{3} \cdot$ Volker M. Arlt $^{4}$. \\ Paul A. White ${ }^{1,2}$
}

Received: 20 September 2017 / Accepted: 17 October 2017 / Published online: 24 November 2017

(c) The Author(s) 2017. This article is an open access publication

\begin{abstract}
Genetic damage is a key event in tumorigenesis, and chemically induced genotoxic effects are a human health concern. Although genetic toxicity data have historically been interpreted using a qualitative screen-and-bin approach, there is increasing interest in quantitative analysis of genetic toxicity dose-response data. We demonstrate an emerging use of the benchmark dose (BMD)-approach for empirically ranking cross-tissue sensitivity. Using a model environmental carcinogen, we quantitatively examined responses for four genetic damage endpoints over an extended dose range, and conducted cross-tissue sensitivity rankings using $\mathrm{BMD}_{100}$ values and their $90 \%$ confidence intervals (CIs). MutaMouse specimens were orally exposed to 11 doses of benzo[a]pyrene. DNA adduct frequency and lac $Z$ mutant frequency (MF) were measured in up to 8 tissues, and Pig- $a$ MF and micronuclei (MN) were assessed in immature (RETs) and mature red blood cells (RBCs). The cross-tissue BMD pattern for lacZ MF is similar to that observed for DNA adducts, and is consistent with an oral route-ofexposure and differences in tissue-specific metabolism and proliferation. The lacZ MF BMDs were significantly correlated with the tissue-matched adduct BMDs, demonstrating a consistent adduct conversion rate across tissues. The BMD CIs, for both the Pig- $a$ and the MN endpoints, overlapped for RETs and RBCs, suggesting comparable utility of both cell populations for protracted exposures. Examination of endpoint-specific response maxima illustrates the difficulty of comparing BMD values for a fixed benchmark response across endpoints. Overall, the BMD-approach permitted robust comparisons of responses across tissues/endpoints, which is valuable to our mechanistic understanding of how benzo[a]pyrene induces genetic damage.
\end{abstract}

Keywords Benzo[a]pyrene $\cdot$ Mutation $\cdot$ Genotoxicity $\cdot$ Clastogenicity $\cdot$ DNA adducts $\cdot$ BMD

Volker M. Arlt and Paul A. White contributed equally.

Electronic supplementary material The online version of this article (doi:10.1007/s00204-017-2099-2) contains supplementary material, which is available to authorized users.

Alexandra S. Long

alexandra.long@canada.ca

1 Mechanistic Studies Division, Environmental Health Science and Research Bureau, Health Canada, 50 Colombine Driveway, Tunney's Pasture, A/L 0803A, Ottawa, ON K1A 0K9, Canada

2 Department of Biology, University of Ottawa, Ottawa, ON, Canada

3 Litron Laboratories, Rochester, NY, USA

4 Analytical and Environmental Sciences Division, MRC-PHE Centre for Environment and Health, King's College London, London, UK

\section{Introduction}

Genetic damage is recognized as an enabler of cancer, and exposure to genotoxic substances is an important human health issue (Hanahan and Weinberg 2011). More specifically, exposures to genotoxicants can contribute to the accumulation of mutations in critical genes, such as tumour suppressor or proto-oncogenes (Fearon 1997; Hemminki et al. 2000; Wang et al. 2012; Kucab et al. 2015, 2016), and this can lead to sustained proliferative signalling, replicative immortality, and evasion of apoptosis and growth suppressors. Although genetic damage can occur and accrue spontaneously through endogenous damage and errors in replication, it is also induced by exposures to environmental genotoxicants. Recent high-profile publications have re-emphasized the importance of extrinsic factors such as 
environmental exposures in determining cancer risk (Alexandrov et al. 2016; Wu et al. 2016).

The pervasive nature of environmental genotoxicants, the recognition in the 1970s and early 1980s that humans are invariably exposed to environmental mutagens, and the established empirical and mechanistic links between genetic damage and carcinogenesis, initiated formal chemical screening programs in Canada, the United States, Japan, and Western Europe (MacGregor et al. 2015a). Importantly, chemical screening for genetic toxicity is now also motivated by recognition that cancer is not the only consequence of somatic mutations. Recent research has demonstrated links between in utero (geno)toxicant exposures and neurodegenerative diseases (Modgil et al. 2014), reproductive defects (Fowler et al. 2008; Mocarelli et al. 2011), child development (Perera et al. 2015) and somatic mosaicism (Erickson 2010; Meier et al. 2016).

Traditional screening for chemically induced genetic toxicity involves high dose exposures followed by binary, qualitative evaluation of the results (i.e., genotoxic or not); little quantitative data analysis is conducted. This screenand-bin approach is based on the assumption that it is not possible to identify a level below which effects are expected to be negligible (i.e., indistinguishable from the ever-present background); and, moreover, that the relationships between exposure and genotoxic effect are linear to zero dose (Health Canada 1994; MacGregor et al. 2015a; Pottenger and Gollapudi 2010). This assumption is increasingly being challenged, and it is now recognized that quantitative analyses of dose-related effects can be used to identify a dose below which the measured effect level is not significantly elevated (Gollapudi et al. 2013; Johnson et al. 2014; MacGregor et al. 2015b; Speit et al. 2000). However, due to the historical bias of examining effects at high doses, with few dose groups, determination of an accurate point-of-departure ( $\mathrm{PoD})$ (i.e., exposure level associated with a pre-defined level of effect) is complicated by the necessity to extrapolate below the tested doses.

The international genetic toxicology community recently examined the use of quantitative dose-response analyses for the determination of genetic toxicity PoD values, as well as their use to determine human exposure limits for regulatory decision-making (Gollapudi et al. 2013; Johnson et al. 2014). Although several methods can be used to analyze dose-response data and generate genotoxicity PoD metrics, the aforementioned works of Gollapudi et al. (2013), Johnson et al. (2014), and MacGregor et al. (2015a) expressed a distinct preference for the benchmark dose (BMD)-approach. The BMD method is a statistical approach for quantitative analysis of dose-response data, whereby a benchmark response (BMR) is selected as a pre-defined effect level (e.g., $10 \%$ greater than control) and the statistically determined BMD is the best estimation of the dose that will elicit this BMR. The approach is flexible with regard to study design (e.g., number of dose groups and number of animals) and critically, the $90 \%$ upper and lower confidence limits on the BMD (i.e., the BMDU and BMDL) enable statistically rigorous BMD comparisons (Crump 1984; MacGregor et al. 2015a; Slob 2002).

The BMD approach can be used for a variety of purposes, including sensitivity ranking, evaluation of mode-of-action (MOA) hypotheses, investigation of empirical relationships between genetic toxicity endpoints, and determination of exposure limits. For example, we recently used BMD 90\% confidence intervals (CIs) to conduct potency rankings across compounds and exposure regimes, and sensitivity rankings across tissues and cell types (Wills et al. 2016a, b). The BMD approach for potency or sensitivity ranking is superior to comparisons based on the no or lowest observed genotoxic effect level (NOGEL or LOGEL), since the PoD derived (i.e., the BMD) is not restricted to the selected dose groups. Moreover, plotting BMD 90\% CIs, and arranging them by mid-point, provides a visually intuitive way to compare BMDs and evaluate trends across compounds, sex, cell type, tissue, exposure regime and other covariates.

The BMD approach has also proved useful for the demonstration of quantitative relationships between genotoxicity endpoints. Such demonstrations, which could investigate relationships between different endpoints or between tissues for a single endpoint, can be used to support the involvement of specific key events in the MOA to the adverse outcome (e.g., cancer). For example, Soeteman-Hernández et al. demonstrated correlations between in vivo genotoxic potency (i.e., BMD for induced mutant or micronucleus frequency) and carcinogenic potency (Hernández et al. 2011; SoetemanHernandez et al. 2016). However, there is a paucity of data to investigate quantitative relationships between several well-understood key events, such as DNA adduct formation, mutations, and chromosomal damage that are triggered by genotoxicants in their carcinogenic MOAs.

Although it is well accepted that a sub-set of DNA adducts will contribute to mutation formation (Hemminki et al. 2000; Hemminki 1993), there is an acute need for research examining quantitative relationships between adduct frequency and mutation frequency, especially at low doses (Hemminki et al. 2000; Sander et al. 2005). The lack of such analyses quantitatively linking in vivo genetic toxicity (e.g., frequency of DNA adducts) with in vivo mutagenicity, across numerous somatic tissues, is likely due to the difficulty of making all the required measurements. Somatic mutations in vivo are rare and they infrequently elicit phenotypic changes; thus chemically induced changes in mutant frequency (MF) are notoriously difficult to detect; moreover, measurement of DNA damage and MF in the same animals constitutes a significant challenge. Although endogenous mutation detection systems do exist, they are 
either laborious, and hence, infrequently used (e.g., Hprt mutations), or restricted to haematopoietic tissues (e.g., Piga). Transgenic rodents (TGRs), which employ a bacterial target gene in a shuttle vector that can readily be recovered from genomic DNA, provide a convenient way to determine in vivo MF in any tissue (Lambert et al. 2009).

In this study, we used the prototypical genotoxic carcinogen benzo[a]pyrene $(\mathrm{BaP})$, four well-characterized genetic toxicity endpoints, and the BMD approach, to scrutinise responses at low doses, rank potencies across tissues, and compare responses across endpoints. To permit simultaneous determination of several endpoints within the same animal, we employed the MutaMouse, a CD2F1 transgenic mouse containing a lac $Z$ target in a lambda shuttle vector (Gossen et al. 1989). We used an extended range of BaP doses (i.e., 11 in total) to examine effects at doses below the region where significant increases in genotoxicity are observed. Although admittedly atypical, the study design employed herein affords improved BMD precision and a concomitant opportunity to robustly compare responses across tissues and endpoints; moreover, to examine empirical relationships between responses of functionally related endpoints (e.g., induced DNA damage and mutations).

\section{Materials and methods}

\section{Animal exposures and tissue collection}

We selected eleven doses of $\mathrm{BaP}$ (CAS \# 50-32-8, purity $\geq 96 \%$; Sigma-Aldrich Canada, Oakville, ON, Canada), with the top doses based on previous work by our group (Lemieux et al. 2011). The selected doses, 0, 0.10, $0.20,0.39,0.78,1.56,3.13,6.25,12.50,25.00$, and $50.00 \mathrm{mg}$ $\mathrm{BaP} / \mathrm{kg}$ body weight (BW)/day, were delivered in highly refined olive oil (Sigma-Aldrich). Adult male MutaMouse specimens (12-13 weeks old) were maintained as described previously (Long et al. 2016). There were 7 animals in each dose group, with 14 animals in the vehicle control group (84 animals total). Mice received $\mathrm{BaP}$ or olive oil by oral gavage at $0.005 \mathrm{ml} / \mathrm{g}$ body weight daily for 28 days. Two days after the final dose, blood was collected from the facial vein for $\mathrm{MN}$ analysis. A 3-day sampling time was employed for the transgene endpoint (OECD 2013), and was also employed for the Pig- $a$ endpoint. Mice were anesthetised with isoflurane gas and blood was collected via cardiac puncture for scoring Pig- $a$ MF. Additionally at this time, blood was collected from 4 positive control mice that were administered $80 \mathrm{mg} \mathrm{ENU} / \mathrm{kg}$ BW i.p., and four vehicle control mice that were administered phosphate buffer as single i.p. injection 3 weeks prior to blood collection. Mice were euthanized by cervical dislocation. Mice were bred, maintained, and treated in accordance with the Canadian Council for Animal
Care Guidelines and Health Canada's Animal Care Committee. Bone marrow, liver, lung, small intestine, and glandular stomach were preserved as described previously (Long et al. 2016). Kidney, spleen, and bladder were flash frozen in liquid nitrogen. All tissues were stored at $-80^{\circ} \mathrm{C}$.

Preliminary data for bone marrow, liver, small intestine, glandular stomach, and lung for the lacZ MF endpoint only were previously published in Wills et al. (2016b); here the dataset is expanded with a further two tissues (i.e., kidney and spleen) for $l a c Z$, and three additional endpoints.

\section{Peripheral blood micronucleus assay}

MicroFlow ${ }^{\circledR}$-BASIC kits (Litron Laboratories, Rochester, NY, USA) were used to prepare blood cells for enumeration of micronucleated reticulocytes (MN-RET) and normochromatic erythrocytes (MN-NCE) at Litron Laboratories, as previously described (Long et al. 2016). Frozen, coded samples were shipped on ice to Litron Laboratories for scoring by flow cytometry using a three-colour labelling method as previously described (Dertinger et al. 2004).

\section{Pig-a mutant scoring in peripheral blood}

Following blood collection via cardiac puncture, $100 \mu$ l of blood was immediately transferred to a $0.5 \mathrm{~mL}$ K2-EDTAcoated microtainer (VWR). Whole blood samples were placed in an ExactPak shipping container and shipped on ice overnight to Litron Laboratories. Flow cytometric scoring of Pig- $a$ MF was conducted at Litron via MutaFlow ${ }^{\circledR}$ Kit reagents according to their published immunomagnetic enrichment method (Dertinger et al. 2011), with modifications for scoring in mouse (Labash et al. 2016). Based on these analyses, the number of Pig- $a$ mutant cells per million were calculated for RETs as well as total red blood cells (RBCs).

\section{DNA extraction}

Bone marrow, glandular stomach, liver, small intestine, and lung were prepared for an overnight digestion in lysis buffer as described previously (Long et al. 2016). Spleen, kidney, and bladder were prepared for overnight lysis and genomic DNA extraction as follows: approximately $1 / 4$ of the spleen, $1 / 2$ of a kidney, or the entire bladder was defrosted on ice and minced into small pieces. The minced tissue was transferred to a tube containing $5 \mathrm{ml}$ lysis buffer [ $1 \mathrm{mM} \mathrm{Na} \mathrm{NaDTA}_{2}$, $100 \mathrm{mM} \mathrm{NaCl}, 20 \mathrm{mM}$ Tris-HCl, pH 7.4, 1\% SDS (w/v)] and incubated overnight at $37{ }^{\circ} \mathrm{C}$ with gentle shaking. Genomic DNA was isolated from lysed tissue using a phenol/chloroform extraction procedure described previously (Douglas et al. 1994; Vijg and Douglas 1996). Isolated DNA 
was dissolved in 50-100 $\mu \mathrm{TE}$ buffer (10 mM Tris pH 7.6, $1 \mathrm{mM}$ EDTA) and stored at $4{ }^{\circ} \mathrm{C}$ until use.

\section{${ }^{32}$ P-postlabelling for DNA adduct analysis}

Bulky DNA adduct formation was analysed in DNA samples from liver, lung, bone marrow, glandular stomach, small intestine, spleen, kidney, and bladder via the nuclease P1 enrichment version of the thin-layer chromatography ${ }^{32}$ P-postlabelling assay (Phillips and Arlt 2014). The procedure was performed as described previously (Krais et al. 2016; Wohak et al. 2016), and results are expressed as DNA adducts $/ 10^{8}$ nucleotides.

\section{Positive selection for lacZ mutants}

The PGal (phenyl- $\beta$-D-galactoside) positive selection assay was carried out for the analysis of lacZ MF in DNA samples from spleen and kidney as previously described (Gossen et al. 1992; Lambert et al. 2005; Vijg and Douglas 1996). MF was calculated as the ratio of mutant plaque forming units (pfu) to total pfu. The lacZ MF could not be scored in bladder as there was insufficient DNA remaining following DNA adduct analysis. The lacZ MF data for bone marrow, glandular stomach, small intestine, liver, and lung was recently published in Wills et al. (2016b), and these data were included in the analyses presented below.

\section{Statistical analysis}

Statistical analysis for the determination of a treatment effect for all endpoints was carried out in SAS v.9.1 (SAS Institute, Cary, NC, USA) by applying a Type 3 Chi-square analysis and employing a Poisson regression, in the same manner as described previously (Long et al. 2016). Post-hoc custom contrasts based on the asymptotic Chi-square distribution of the likelihood ratio statistic were conducted to compare each dose group with the control.

\section{Benchmark dose modelling}

BMD analyses were conducted using the PROAST software (version 50.9-http://www.proast.nl). Dose-response data were analysed using a family of nested exponential models (Slob 2002) recommended by the European Food Safety Authority for the assessment of continuous data (EFSA 2009). PROAST uses the likelihood ratio test to select the optimal model, with increasingly complex models using additional parameters only accepted if the difference in loglikelihood exceeds the critical value of $p<0.05$. The BMR selected for the current analyses (i.e., $100 \%$ or a two-fold increase in the response relative to control), was chosen as it is commonly used for the assessment of genotoxicity data, and because it tended to lie within the range of experimental observation in the datasets herein as was thus 'optimal' for deriving CIs for sensitivity comparison (Wills et al. 2016a). The BMDL and BMDU values represent the lower and upper bounds of the two-sided $90 \%$ CI of the BMD, respectively, with the difference between the BMDU and BMDL defining the uncertainty in the BMD estimate and, therefore, its precision. As employed in previous work, CI plots arranged by the geometric midpoint of the BMDL-BMDU interval were utilised to permit robust sensitivity comparisons that account for estimation uncertainty (Bemis et al. 2016; Wills et al. 2016a).

To evaluate the relationship between lacZ BMDs and adduct BMDs, the visual approach used by Bemis et al. (2016) and Soeteman-Hernández et al. (2016) was employed. This approach simply draws a line with unity slope through the double-log plot; the unity slope translates into a proportional relationship between the endpoint BMDs on the original axes scales.

\section{Results}

No overt signs of toxicity (i.e., body weight change, liver somatic index) were observed in any dose group, including controls. A significant level of induction of each genetic damage endpoint was observed in all tissues examined, although the responses occurred at different dose levels and the magnitude of the response varied across endpoints. Using PROAST, we employed the exponential model family to derive the $\mathrm{BMD}_{100}$ and accompanying $90 \%$ CIs (i.e., the $\mathrm{BMDL}$ and $\mathrm{BMDU}$ values). The $\mathrm{BMD}_{100}$, BMDL, BMDU, along with the BMDU-BMDL ratio for each tissue and endpoint are summarised in Supp. Table I, and BMD model fits for each analysis are presented in Supp. Figure 1a-d. The CIs (i.e., range between the BMDL to BMDU) bounding the $\mathrm{BMD}_{100}$ values were used for comparative evaluations of tissue sensitivities.

\section{DNA adduct frequency}

Using an external BaP-diol-epoxide-DNA standard (Phillips and Castegnaro 1999), the major DNA adduct detected was identified as dG- $N^{2}$-BPDE (10-(deoxyguanosin- $N^{2}$-yl)-7,8,9trihydroxy-7,8,9,10-tetrahydro-BaP), with BaP-DNA adducts being detected in all seven tissues examined (Supp. Figure 2). The first dose in which we observed a significant increase in adduct frequency over control (i.e., the LOGEL) was $0.20 \mathrm{mg} / \mathrm{kg} \mathrm{BW} /$ day for spleen, $0.39 \mathrm{mg} / \mathrm{kg} \mathrm{BW} /$ day for bladder, $0.78 \mathrm{mg} / \mathrm{kg} \mathrm{BW} /$ day for bone marrow, liver, small intestine, lung, and kidney, and $1.56 \mathrm{mg} / \mathrm{kg}$ BW/day for glandular stomach (Fig. 1a; Supp. Figure 3). The highest 


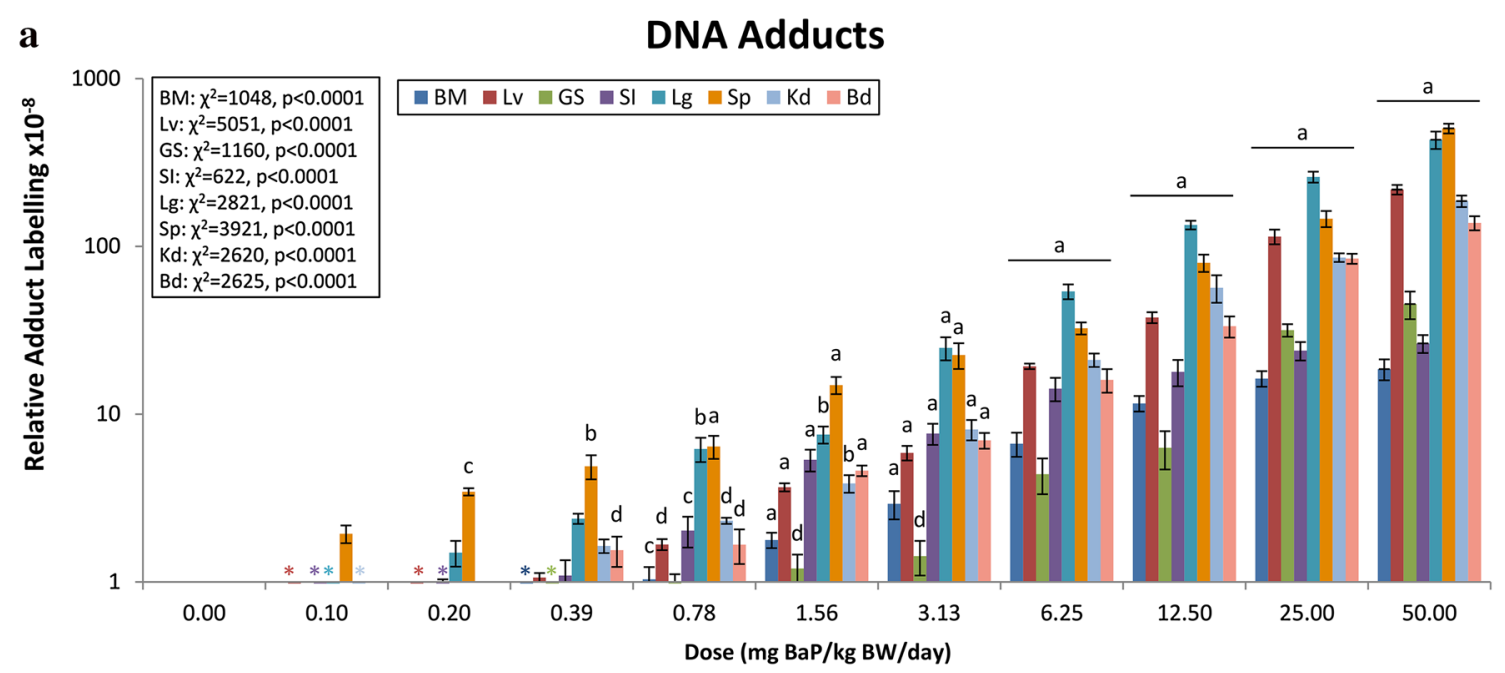

b

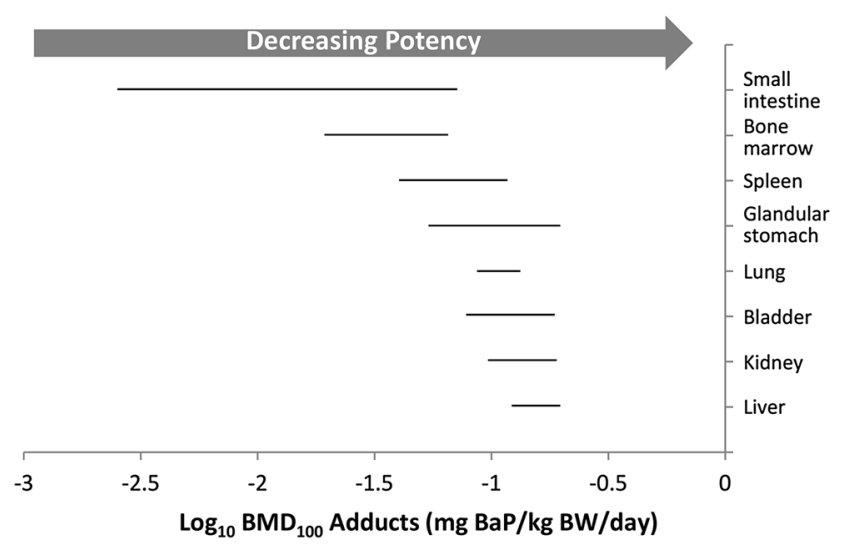

Fig. 1 The frequency of BaP-induced DNA adducts was evaluated in 8 tissues. a BaP dose-response data ( \pm standard error) for DNA adducts plotted using a $\log _{10} \mathrm{y}$-axis for better visualisation of the responses across all doses. Statistical results for the overall doseresponse relationship are presented for each tissue. The level of significance for the custom contrast results for each dose vs. control are indicated as follows: $a=p<0.0001 ; b=p<0.001 ; c=p<0.01$; $d=p<0.05$. $B M$ bone marrow, $L v$ liver; $G S$ glandular stomach; $S I$

fold change increase in DNA adduct levels over control was observed in spleen (506-fold), followed by lung (433-fold), liver (219-fold), kidney (187-fold), bladder (139-fold), glandular stomach (46.3-fold), small intestine (27.4-fold), and bone marrow (19.6-fold).

To visualize the difference in tissue sensitivities, the BMD CIs for each tissue were plotted using a $\log _{10}$-scale (Fig. 1b). In this way, tissues with non-overlapping BMD CIs can be sequentially ranked by sensitivity, with decreasing sensitivity shown from left to right (i.e., lowest to highest BMD). This method for the illustration of sensitivity trends is superior to the common approach of simply listing the BMD/BMDL/BMDU values in a table (Supp. Table I), as upon inspection of Fig. 1b it is immediately apparent that the sensitivity order is: small intestine/bone small intestine; $L g$ lung; $S p$ spleen; $K d$ kidney; $B d$ bladder. Asterisk indicates where responses were below 1 , and thus are obscured on a $\log _{10}$ scale. Supp. Figure 3 shows dose-response data plotted on a linear scale with a restricted $y$-axis to visualise the low-dose responses. b $\mathrm{BMD}_{100}$ values and two-sided $90 \%$ CIs (i.e., the range between the BMDL and BMDU) determined using the exponential model for DNA adducts. BMDs can be considered different where CIs do not overlap

marrow/spleen/glandular stomach/lung/bladder/kidney/ liver. Due to the relatively large BMD CI for some tissues (e.g., 5 of 8 tissues had BMDU-BMDL ratios over 2, Supp. Table I), there is some overlap in the BMD range of all adjacent tissues. However, it is still possible to obtain mechanistic information from these results; and, moreover, conclude that the sensitivity of small intestine and bone marrow are significantly higher than lung, bladder, kidney, and liver. It is also interesting to note that the sensitivity order obtained via BMD-modelling is not the same as the order of tissues according to the level of induced response (i.e., maximum fold-change over control), nor the order determined using lowest significant dose (i.e., the LOGEL). 


\section{lacZ mutant frequency}

A significant induction in lacZ MF was observed in all tissues examined, with LOGELs of $1.56 \mathrm{mg} / \mathrm{kg}$ BW/day for small intestine, $3.13 \mathrm{mg} / \mathrm{kg} \mathrm{BW} /$ day for bone marrow and spleen, $6.25 \mathrm{mg} / \mathrm{kg} \mathrm{BW} /$ day for lung and glandular stomach, $12.5 \mathrm{mg} / \mathrm{kg} \mathrm{BW} /$ day for kidney, and $25 \mathrm{mg} / \mathrm{kg}$ BW/day for liver (Fig. 2a). The highest fold change increase over control was observed in small intestine (208-fold), followed by bone marrow (120-fold), spleen (81.0-fold), glandular stomach (28.6-fold), liver (14.6-fold), lung (14.1-fold), and kidney (5.0-fold). As Fig. 2b illustrates, there were considerable differences in BMDs across tissues, with the sensitivity order as follows: small intestine $>$ spleen or bone marrow $>$ glandular stomach or lung $>$ liver or kidney. Despite minor differences, it is apparent that this sensitivity trend is similar to that observed for DNA adduct frequency. However, for the
lacZ endpoint the BMDs were more precise (i.e., all BMDUBMDL ratios below 2; Supp. Table I), which resulted in fewer overlapping CIs. As a result, it is possible to distinguish $l a c Z$ sensitivity values between additional tissues, and in fact, to visualise three discrete groupings of tissues (i.e., small intestine $>$ bone marrow/spleen $>$ kidney/liver/lung/ stomach). In this case, the sensitivity order is fairly similar to the order according to induced response and LOGEL.

\section{Pig-a mutant frequency in peripheral blood}

Pig- $a$ mutant phenotype frequency was examined in both RETs and RBCs. A significant positive increase was observed in both cell populations, with the first significant response (i.e., the LOGEL) appearing at $12.5 \mathrm{mg} /$ $\mathrm{kg} \mathrm{BW/day} \mathrm{in} \mathrm{both} \mathrm{RETs} \mathrm{and} \mathrm{RBCs} \mathrm{(Fig.} \mathrm{3a).} \mathrm{The} \mathrm{fold-}$ increase over control observed for RBCs (69.7-fold) was

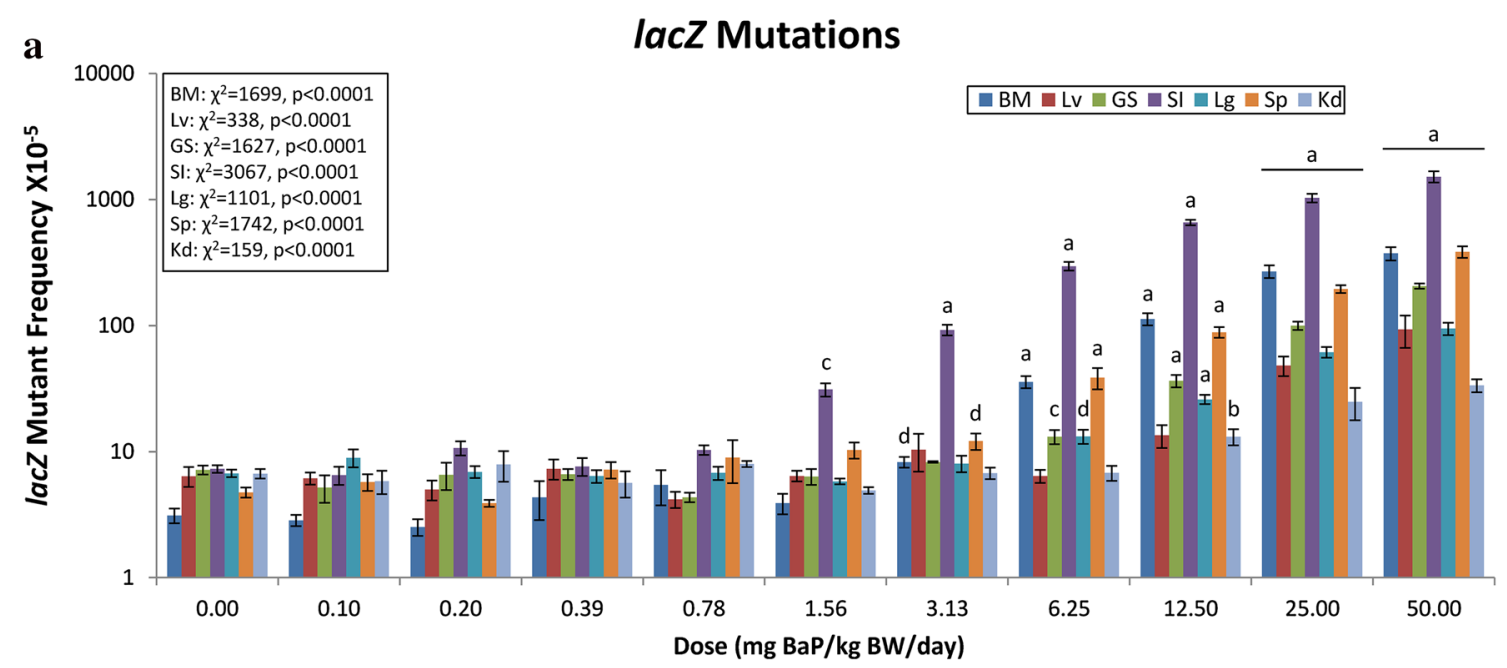

b

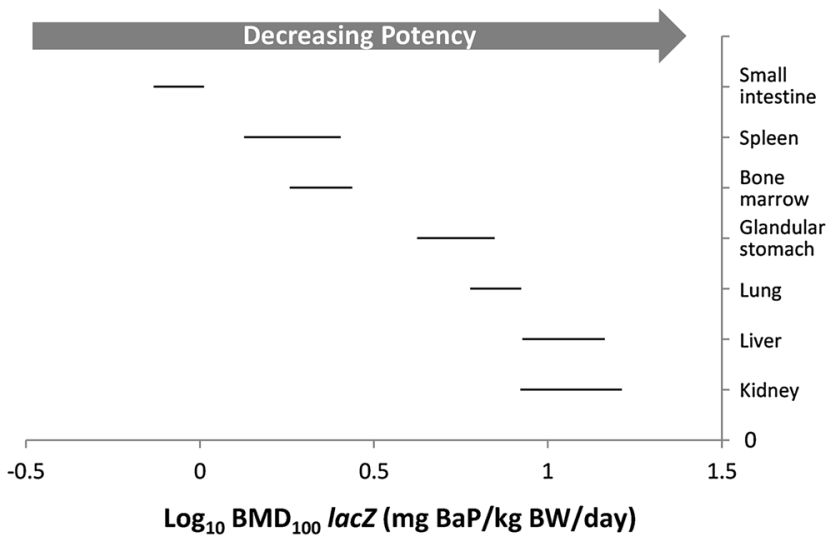

Fig. 2 The frequency of BaP-induced lac $Z$ mutants was evaluated in seven tissues. a $\mathrm{BaP}$ dose-response data ( \pm standard error) for lac $Z$ mutations, plotted using a $\log _{10} \mathrm{y}$-axis for better visualisation of the responses across all doses. Statistical results for the overall doseresponse relationship are presented for each tissue. The level of significance for the custom contrast results for each dose vs. control are indicated as follows: $a=p<0.0001 ; b=p<0.001 ; c=p<0.01$; $d=p<0.05$. BM bone marrow; $L v$ liver; $G S$ glandular stomach; $S I$ small intestine; $L g$ lung; $S p$ spleen; $K d$ kidney. b $\mathrm{BMD}_{100}$ values and two-sided $90 \%$ CIs (i.e., the range between the BMDL and BMDU) determined using the exponential model for lacZ mutations. BMDs can be considered different where CIs do not overlap 
Fig. 3 The frequency of BaPinduced Pig- $a$ mutant phenotype was evaluated in peripheral blood. a $\mathrm{BaP}$ dose-response data ( \pm standard error) for Pig-a mutations. Statistical results for the overall dose-response relationship are presented for both cell populations. The level of significance for the custom contrast results for each dose vs. control are indicated as follows: $a=p<0.0001 ; b=p<0.001$; $c=p<0.01 ; d=p<0.05$. $R E T$ reticulocyte; $R B C$ red blood cell. b $\mathrm{BMD}_{100}$ values and two-sided $90 \%$ CIs (i.e., the range between the BMDL and BMDU) for Pig- $a$ mutations for both cell populations Where CIs overlap tissue responses cannot be considered different
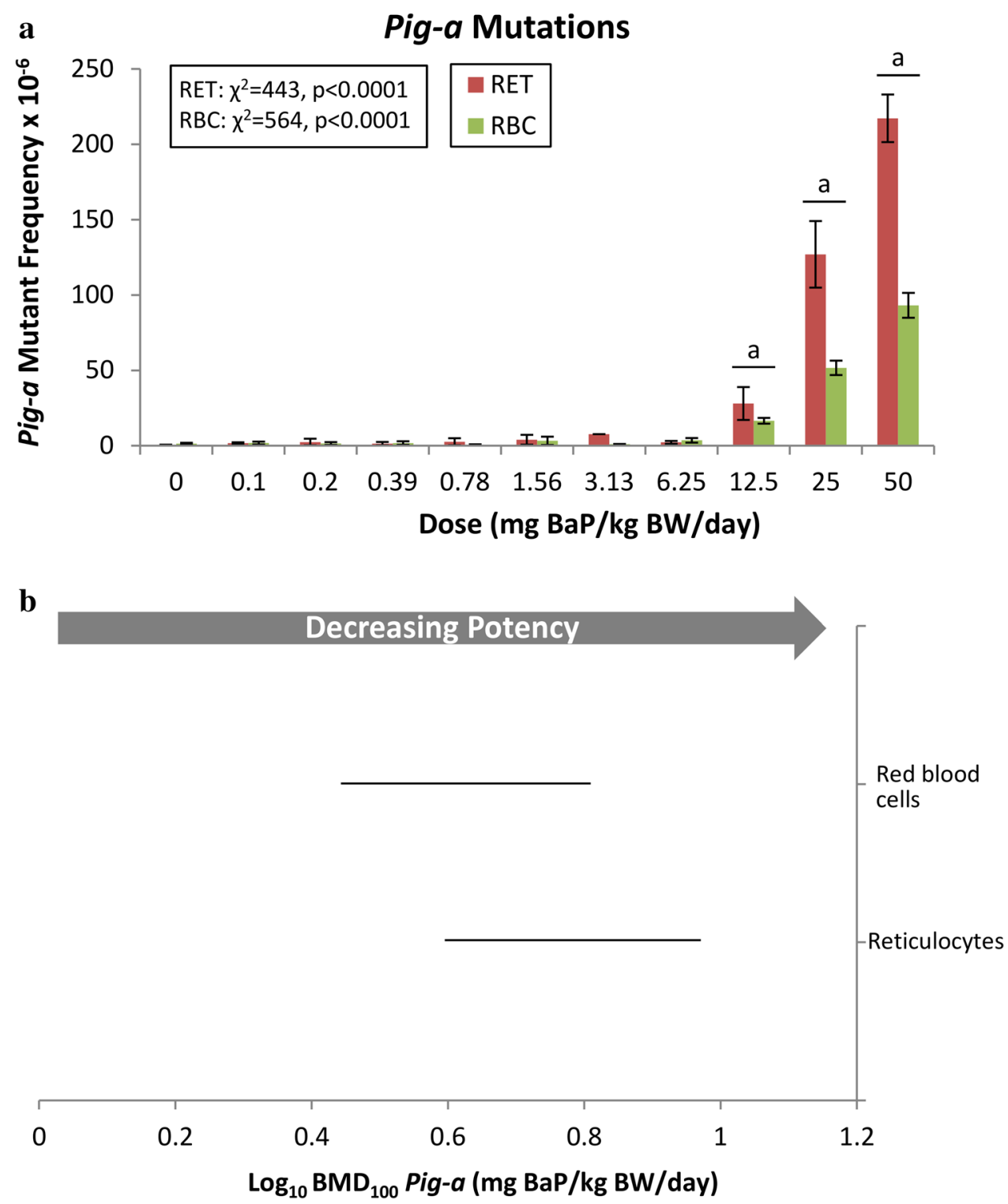

only $1 / 5$ as high as for RETs (385.5-fold). The BMD CIs for RETs and RBCs overlapped (Fig. 3b), therefore, a sensitivity order could not be established. This is interesting given the large difference in response magnitudes; however, the trend across these two cell populations is analogous to the observed cross-tissue trend in sensitivity to adduct formation (i.e., overlapping BMD ranks). In this case, issues related to the detection of the Pig-a MF resulted in reduced sample size that likely contributed to increases in the BMD CIs. In fact, the Pig- $a$ BMDUBMDL ratio is over 2 for both cell populations, whereas the lacZ BMDU-BMDL ratio is below 2 for all tissues examined.

\section{Percent micronuclei in red blood cells}

The frequencies of micronucleated RETs and NCEs were examined to assess BaP-induced chromosomal damage. A significant increase in the percent micronucleated cells was observed in both RETs and NCEs at $3.13 \mathrm{mg} / \mathrm{kg}$ BW/day (Fig. 4a). A slightly higher fold-change increase over control was observed in RETs (4.5-fold), in comparison with NCEs (3.7-fold). The ranges between the BMDL and BMDU overlapped (Fig. 4b), therefore, a sensitivity order could not be determined. The ratio of BMDU to BMDL was well below 2 , indicating that $\mathrm{BaP}$ is similarly clastogenic in both cell populations. 
Fig. 4 The frequency of BaPinduced $\mathrm{MN}$ was evaluated in peripheral blood. a $\mathrm{BaP}$ dose-response data $( \pm$ standard error) for micronuclei. Statistical results for the overall doseresponse relationship are presented for both cell populations. The level of significance for the custom contrast results for each dose vs. control are indicated as follows: $a=p<0.0001$; $b=p<0.001 ; c=p<0.01$; $d=p<0.05$. RET reticulocyte; NCE normochromatic erythrocyte. $\mathbf{b} \mathrm{BMD}_{100}$ values and two-sided $90 \%$ CIs (i.e., the range between the BMDL and BMDU) for $\%$ micronuclei for both cell populations. Where CIs overlap tissue responses cannot be considered different

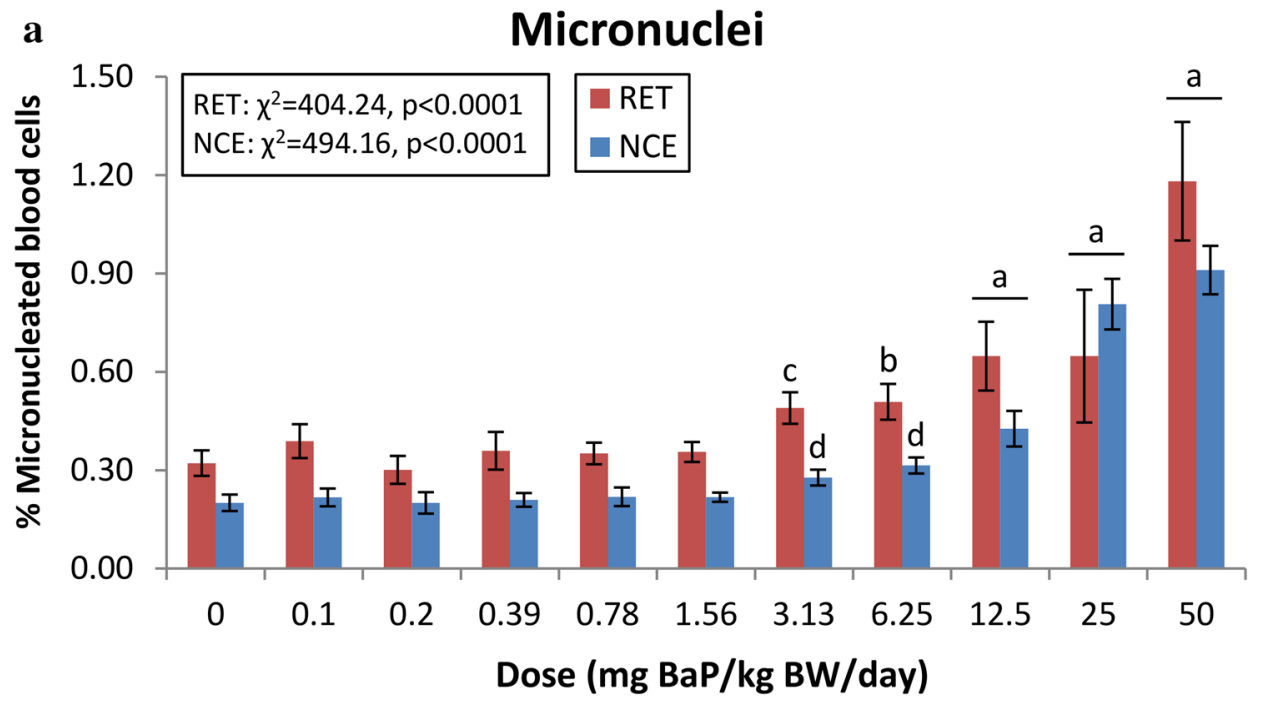

b

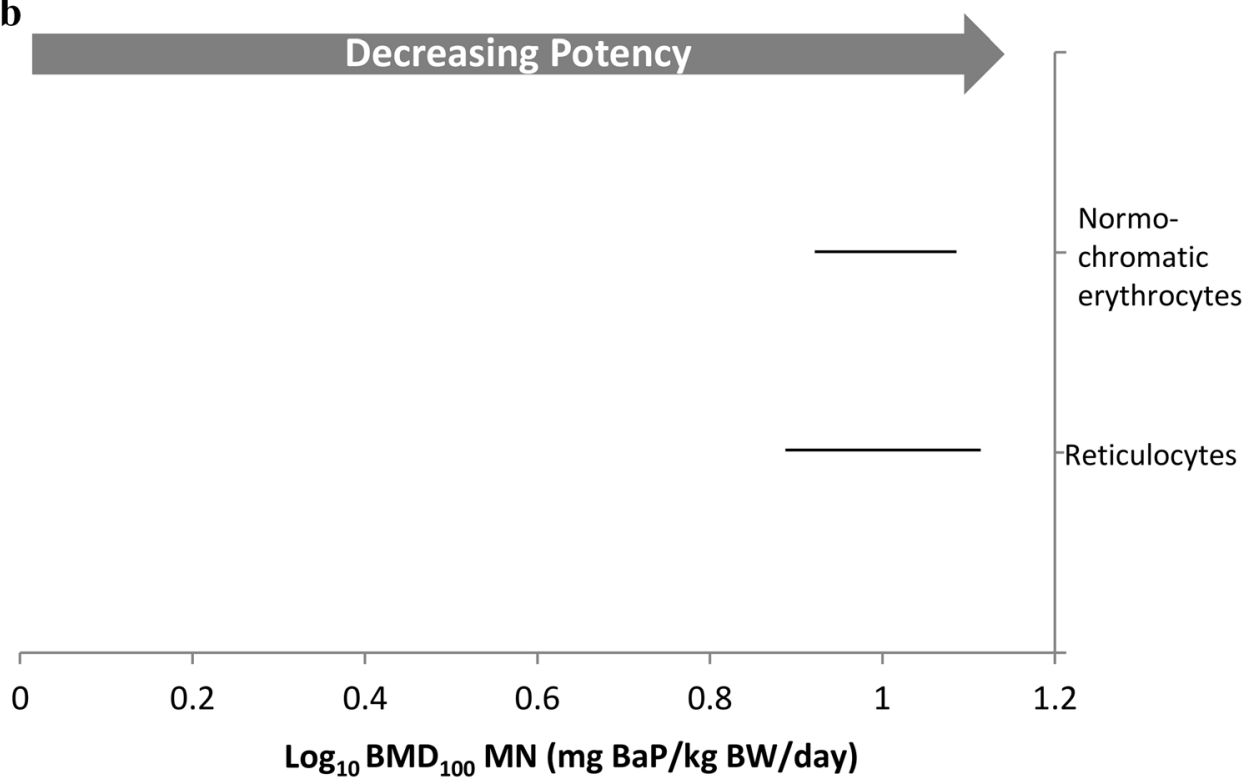

\section{Comparisons of endpoint-specific BMDs for hematopoietic tissues}

Finally, we compared sensitivity across each endpoint for hematopoietic tissues. To do this, the $90 \%$ CIs for each hematopoietic tissue $\mathrm{BMD}_{100}$ were plotted together for visual comparison across the endpoints examined (Fig. 5a). The figure shows a progression of $\mathrm{BMD}_{100}$ values across endpoints from DNA adducts (i.e., lowest BMD), to lac Z and Pig-a mutants at doses approximately 25- to 90 -fold higher, and finally, to chromosome damage at doses 2- to 4.5-fold higher than the mutant endpoints and 150- to 350fold higher than for DNA adducts (Supp. Table I). Thus, the observed pattern of BMDs in hematopoietic tissues seems consistent with the sequence of key events leading from genetic damage to cancer.

Although Fig. 5a supports the contention that sequential genotoxic events precede tumor formation (Fukushima et al. 2016; MacGregor et al. 2015b) the manner in which the data are presented raises fundamental questions about the validity of such cross-endpoint comparisons. Figure $5 \mathrm{~b}$ uses identical fixed y-axes to compare the modelled dose-responses for each endpoint in hematopoietic tissue (RBCs only for Pig- $a$, NCEs only for MN). By plotting the responses on the same $y$-axis scale, it becomes readily apparent that the inducible range in response varies considerably across endpoints (e.g. a small dynamic range in inducible response is particularly noticeable for the micronucleus endpoint). Additionally, 


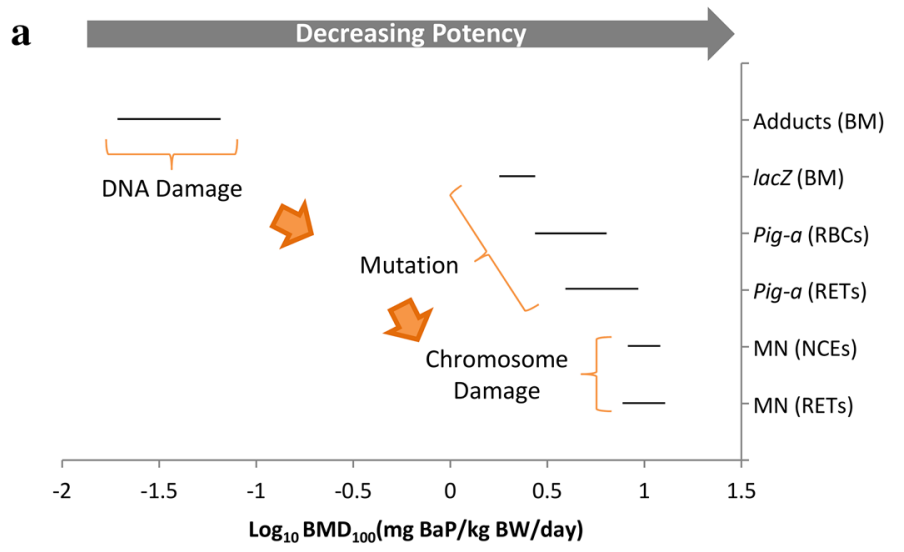

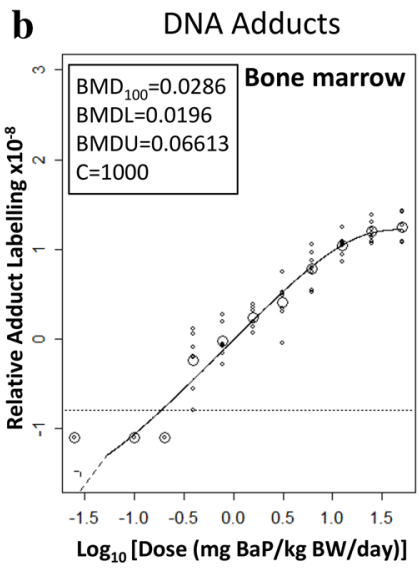

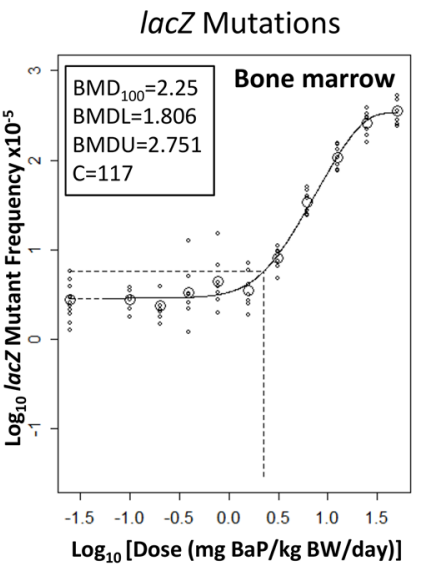

Fig. 5 The observed pattern of hematopoietic tissue BMDs showing important differences in the maximum response across endpoints. a $\mathrm{BMD}_{100}$ values and two-sided $90 \%$ confidence intervals (i.e., the range between the BMDL and BMDU) for each endpoint in hematopoietic tissue. b Illustration of fitted functions on a fixed y-axis

model parameter ' $c$ ' displayed in the inset, which is the model-determined estimate of the maximum response, shows nearly a 10 -fold reduction between the DNA adduct and MF endpoints, and an approximately 25 -fold reduction between the MF and micronucleus endpoints (Fig. 5b).

\section{Empirical relationship between genotoxic sensitivity and mutagenic sensitivity}

When visually comparing the dose-response data for DNA adduct frequency (Fig. 1a) with that for lacZ MF (Fig. 2a), there is no apparent empirical relationship between the tissue-specific induced damage levels. To examine the empirical relationship between these two endpoints, tissue-matched $\mathrm{BMD}_{100}$ values, and their associated $90 \%$ CIs, were plotted against each other. To quantitatively scrutinise the correlation on the double-log axes, a diagonal line with unity slope (i.e., slope $=1$ ) was overlaid on the plotted data (Fig. 6). If
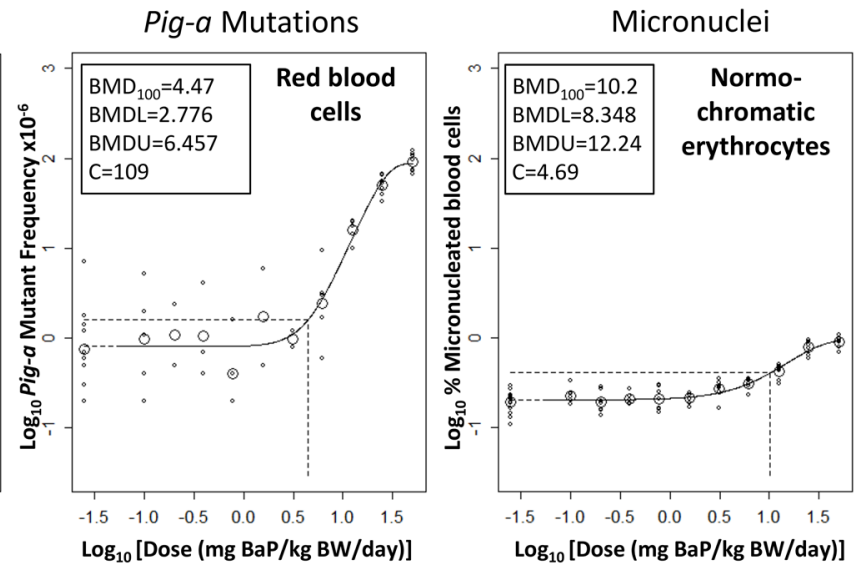

showing variations in maximum response, indicated by model parameter ' $c$ ' (inset), across endpoints. The horizontal dashed lines indicate the BMR on the $Y$-axis, and the vertical dashed lines indicate the BMD on the $X$-axis

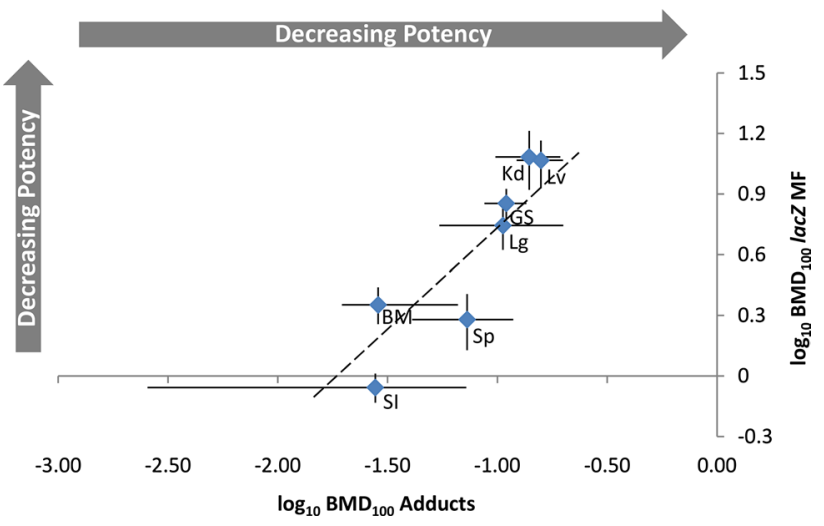

Fig. 6 The empirical relationship between genotoxic sensitivity and mutagenic sensitivity of $\mathrm{BaP}$ (i.e., $\mathrm{BMD}_{100}$ values and two-sided $90 \%$ CIs for the DNA adduct endpoint vs. tissue-matched $\mathrm{BMD}_{100}$ values and two-sided $90 \% \mathrm{CIs}$ for the lacZ mutation endpoint). A line with unity slope is indicated, which, on a double-log plot, demonstrates proportionality between the responses. $B M$ bone marrow; $L v$ liver; $G S$ glandular stomach; $S I$ small intestine; $L g$ lung; $S p$ spleen; $K d$ kidney 
the BMDs for the various tissues scatter randomly around the unity line, and the unity line appears to be a good representation of the data, this shows that the mutant and adduct BMDs are proportionally related on the original scales. The analysis, which is shown in Fig. 6, indeed demonstrated a proportional relationship between genotoxic sensitivity (i.e., induction of DNA adducts), and mutagenic sensitivity (i.e., induction of lac Z mutants) across seven tissues. Critically, this proportionality suggests that, despite large differences in cross-tissue BMDs for a given endpoint, tissue-specific conversion of adducts to mutations is likely consistent.

As cellular replication is a necessary factor for mutation fixation, we also wanted to investigate the influence of cellular proliferation on the conversion of DNA adducts to mutants. As part of our standard experimental protocol, we evaluated proliferation rate, as Ki-67 index, in liver, lung, and small intestine (Supp. Methods). The Ki-67 index plotted against the ratio of DNA adduct BMD to lacZ MF BMD for these three tissues (Supp. Figure 4), is positively correlated. Although this correlation is based on only three tissues, it supports the notion that cellular proliferation rate affects the tissue-specific conversion of BaP-induced DNA adducts to mutations.

\section{Discussion}

The quantitative assessment of genetic toxicity data is a rapidly advancing field, and the emerging application of the BMD-approach to derive PoDs has well-described advantages for regulatory decision-making and the protection of human health. Here, we present an advanced approach for BMD-modeling that allows for robust cross-tissue sensitivity ranking, thereby contributing important quantitative support for tissue-specific genotoxic effects. More specifically, this study used the BMD-approach to model BaP-induced in vivo genetic toxicity dose-response relationships across several tissues and an expanded dose range, and derived $\mathrm{BMD}_{100}$ values and their associated $90 \%$ CIs for each tissue/endpoint combination. We subsequently employed the BMD CIs to conduct sensitivity ranking across eight tissues for DNA adducts, seven tissues for lacZ mutants, and 2 peripheral blood cell populations for both Pig- $a$ MF and MN. As discussed below, examinations of tissue rankings for each endpoint, and empirical relationships between the endpoints, permitted general statements about the fundamental nature of the endpoints examined and the mechanistic relationships between the damage types.

It is well recognized that $\mathrm{BaP}$ primarily induces tumors via a genotoxic mode-of-action; specifically, via the conversion of bulky DNA adducts to point mutations that confer the hallmark properties of a cancerous cell (Hanahan and Weinberg 2011; IARC 2010b). Although not the primary mechanism, $\mathrm{BaP}$ is also known to induce micronuclei, as double strand breaks may be formed as a result of replication fork stalling and collapse (Bi et al. 2005). Following oral exposure, $\mathrm{BaP}$ has been shown to induce carcinomas in the oral cavity, forestomach, liver, and small intestine of male and female Wistar rats, and kidney, mammary, and skin carcinomas in male Wistar rats (Kroese et al. 2002). Oral administration to various mouse strains resulted in tumours in lymphoid and haematopoietic tissues, as well as in lung, forestomach, liver, esophagus, and tongue (IARC 2012). BaP also caused forestomach carcinomas, malignant lymphomas in lymphatic organs including the spleen, and bronchiolar-alveolar hyperplasia in the lung of male MutaMouse specimens orally exposed for only 5 days (Hakura et al. 1998). It is, therefore, not unexpected that we were able to detect significant increases in BaP-induced genotoxicity for all four endpoints in all tissues/cell populations examined, namely DNA adducts and lac $Z$ mutants in bone marrow, glandular stomach, small intestine, liver, lung, kidney, spleen, and bladder (adducts only); as well as Pig- $a \mathrm{MF}$ and chromosome damage in peripheral blood cells. With respect to DNA damage, we were able to detect a significant increase in DNA adducts at $0.20 \mathrm{mg} \mathrm{BaP} / \mathrm{kg} \mathrm{BW} /$ day, the lowest oral dose used to date to investigate the in vivo genotoxicity of BaP. This robust genotoxic response demonstrates the utility of the MutaMouse TGR assay for simultaneously investigating several, complementary genetic toxicity endpoints across numerous tissues.

Ranking sensitivity across the measured tissues lends support for mechanistic understanding of the toxicological properties of the compound evaluated. In this study, we observed that the Pig- $a$ and MN BMD CIs overlapped for RETs and RBCs/NCEs, and, therefore, a sensitivity order could not be established between the two cell populations. This may simply be due to the accuracy of the measurement of these endpoints, with larger CIs being more likely to result in overlap. However, for the $\mathrm{MN}$ endpoint in particular, the BMDU-BMDL ratio is below 2 and is quite similar for both cell populations, therefore, alternatively, this may indicate that RETs and NCEs are equally sensitive to MN induction by BaP. Therefore, that there may be comparable utility in examining either cell population for study designs that involve protracted exposures, such as the one conducted here. Our novel approach to data analysis makes a direct comparison of our results with other publications using these endpoints difficult. However, in a recent paper we employed the BMD method to examine dose-response data from a Pig- $a$ study examining the genotoxicity of $N$-ethyl$\mathrm{N}$-nitrosourea, and in that case, the BMD CIs for RBCs and RETs overlapped (Wills et al. 2016b), as they did in the current study. Conversely, the CIs for RBCs sampled at different time points were distinct (Wills et al. 2016b), which highlights that sampling time appears to be more important 
for RBCs than for RETs. Notably, for both the Pig- $a$ and MN endpoints, far fewer RETs are interrogated than NCEs/ RBCs, and this contributes to larger CIs. Additional use of the BMD approach will permit similar cross-cell comparisons for different species, experimental designs, and compounds.

The DNA adduct and lacZ MF sensitivity rankings resulted in very similar cross-tissue patterns; however, there was considerably more overlap in CI range across tissues for DNA adducts than for lacZ MF. This is likely a result of the fact that the lac $Z$ MF data permit determination of more precise BMDs (as demonstrated by the smaller BMDUBMDL ratio), allowing for greater sensitivity discrimination between tissues.

For both DNA adducts and lacZ MF, the cross-tissue pattern in responses is likely controlled by four factors: (1) tissue contact, (2) tissue-specific metabolism and the extent of systemic circulation of the parent compound and activated metabolites, (3) tissue-specific proliferation rate, and (4) tissue-specific differences in DNA repair capacity. As discussed in our recent manuscript (Wills et al. 2016b), the fact that small intestine was the most sensitive tissue for induction of lac $Z$ mutants, and similarly, as seen here, for DNA adducts, is consistent with an oral route of exposure and the known metabolic capacity of this tissue. $\mathrm{BaP}$ itself is not DNA-reactive. Its major genotoxic pathway (i.e., via cytochrome P450 CYP1A1/1A2/1B1 metabolism) is induced following aryl-hydrocarbon (AhR)-agonism (Shimada et al. 2002; Shimada and Fujii-Kuriyama 2004; Xue and Warshawsky 2005), and leads to the conversion of $\mathrm{BaP}$ into the genotoxic metabolite BaP-7,8-dihydrodiol9,10-epoxide (BPDE). BPDE exerts its mutagenic effect by covalently binding primarily to purines, causing a bulky DNA adduct, which if not repaired prior to DNA replication, can result in a mutation (IARC 2014). Two alternate activation pathways for $\mathrm{BaP}$ are also recognized, namely the PAH-radical-cation pathway, which results in depurinating adducts, and the ortho-quinone pathway, which can generate covalent DNA adducts or oxidative DNA damage (Penning 2014). However, this study, which employed ${ }^{32} \mathrm{P}$-postlabeling, only examined the frequency of BPDE-type adducts. Although ingested $\mathrm{BaP}$ would reach the stomach first, the small intestine is known to have much higher levels of Cyplal expression (Choudhary et al. 2003; Renaud et al. 2011) and, therefore, absorption by the small intestine would likely result in greater conversion to BPDE, a concomitant increase in damage in this tissue, and a higher sensitivity (i.e., lower BMD) in comparison with stomach (Figs. 1b, $2 \mathrm{~b})$. Furthermore, $\mathrm{BaP}$ is known to undergo enterohepatic circulation (Miller and Ramos 2001; Ramesh et al. 2004), which causes cycling of $\mathrm{BaP}$ and its activated metabolites between the liver and the small intestine via the bile. This would permit re-exposure of the small intestine and liver to
BPDE, leading to an increase in bulky adducts and, in turn, mutations. Taken together, the high level of tissue contact and effective metabolism in this tissue would certainly contribute to the high sensitivity in small intestine, as seen here.

As with the site-of-contact tissues, the spleen and bone marrow were quite sensitive to the induction of both DNA adducts and lac $Z$ mutants. These are both distal tissues that require systemic circulation of $\mathrm{BaP}$ and/or activated metabolites for exposure to occur. $\mathrm{BaP}$ is well known to induce significant immunotoxicity in rodent models (Blanton et al. 1986; De Jong et al. 1999; Dean et al. 1983; Ginsberg et al. 1989), which appears to be at least partially mediated by cytotoxicity related to DNA adduct formation (Ginsberg et al. 1989). The lymphatic system, including the spleen, is also a target organ for tumors (lymphomas) in orally exposed MutaMouse (Hakura et al. 1998), and XPA-deficient mice (IARC. 2010a; Van Oostrom et al. 1999). CYP1B1 in the spleen and bone marrow appears to mediate the conversion of BaP to BPDE (Heidel et al. 1998; Uno et al. 2006) with several studies also suggesting the possibility that splenic exposure to BPDE is also occurring as a result of extrasplenic metabolism (Ginsberg et al. 1989; Ginsberg and Atherholt 1990). Specifically, BPDE in the blood can be sequestered by the serum (Ginsberg and Atherholt 1989) and transported to the spleen, where it is released and taken up by splenocytes (White et al. 1994). The results presented herein likely indicate that substantial levels of $\mathrm{BaP}$ are available for systemic circulation, and support the high sensitivity observed for both bone marrow and spleen.

The cross-tissue sensitivity ranking for the lacZ endpoint also highlights the likely role of tissue-specific proliferation, since the sensitivities for tissues with higher proliferative rates (i.e., small intestine, spleen, bone marrow, glandular stomach) were higher than tissues with slower rates of proliferation (i.e., lung, liver, kidney). For example, the sensitivity of the hepatic lac $Z$ response is the lowest (i.e., highest BMD), and this is consistent with a relatively low proliferation rate in comparison with the other tissues examined. In order for bulky adducts to result in sequence changes, DNA replication is a necessary process, therefore, tissues that are not actively undergoing cellular proliferation would accrue fewer mutants in a given period of time, whereas a tissue with a higher mitotic index would be likely to accrue far more mutants. It is known that spleen (Muskhelishvili et al. 2003), bone marrow (White et al. 2017), glandular stomach (Merritt et al. 1997; Ozkan et al. 2001; Radulescu et al. 2010; Snipes 1967), and small intestine (Muskhelishvili et al. 2003; White et al. 2017) have mitotic indices that are at least an order of magnitude higher than those of slower proliferating tissues such as liver (White et al. 2017), lung (Shami and Evans 1992), and kidney (Eldridge and Goldsworthy 1996). These higher replication rates would be expected to contribute to higher mutagenic efficiency (i.e., 
conversion of stable DNA adducts to mutations), higher mutant responses for a given dose, and a concomitantly lower BMD (i.e., lower sensitivity), which is consistent with our results. In fact, when we plotted the Ki-67 index for liver, lung, and small intestine against the ratio of the $\mathrm{BMD}_{100}$ of DNA adducts to $\mathrm{BMD}_{100}$ of lacZ mutations (Supp. Figure 4), we obtained a significant positive correlation. Taken together, the data presented here and in the literature highlight the importance of tissue-specific cellular proliferation in the conversion efficiency of stable DNA adducts to mutations.

The tissue-specific difference in DNA-repair capacity is also likely to contribute to the observed sensitivity pattern across tissues. Recent in vitro studies of potent alkylating agents have demonstrated that inactivation of $\mathrm{O}^{6}$-methylguanine DNA methyltransferase (MGMT) can shift the PoD for mutation and chromosome damage to the left (i.e., more potent) (Thomas et al. 2013; Zair et al. 2011), whereas murine overexpression of the same repair pathway moves the PoD for tumor formation induced by alkylating agents significantly to the right (i.e., less potent) (Becker et al. 2014). Although differences in repair capacity across various tissues have not been fully explored, it is likely that tissue-specific differences in the presence and activity of certain DNA repair genes will affect the rate of conversion of bulky adducts to mutations. This is consistent with the aforementioned work of Thomas et al. (2015), which noted that the four key proteins involved in nucleotide excision repair (i.e., the pathway associated with BPDE removal) can be induced by genotoxic stress.

The direct comparison of BMDs across endpoints is an approach used to permit ranking of mechanistically sequential endpoints (Fukushima et al. 2016; Moffat et al. 2015; Thomas et al. 2007). The approach, which is borrowed from chemical risk assessors' practice of employing the most sensitive endpoint (i.e., lowest NOAEL) for regulatory decision-making, involves ordering endpoints that represent a series of plausible key events, and then comparing PoD metrics across these endpoints. When the $\mathrm{BMD}_{100}$ values calculated here are compared across all hematopoietic tissue endpoints (Fig. 5a), the observed BMD pattern is consistent with the sequence of key events leading from genetic damage to cancer. At first glance this is intuitive, as we expect DNA adducts to occur at a dose that is only limited by test article absorption, metabolism, and distribution, and tissue exposure to activated metabolites. Adducts may be repaired, however; and only when this response becomes overwhelmed, presumably at a higher dose, would we expect to see mutations and/or chromosome damage. Thus, the BMD for the next endpoint in the series (i.e., mutations) would be expected to be equal to or higher than that for adducts (Meek et al. 2014), as we found here with the BMD for lacZ mutants in bone marrow, which preceded that for Pig- $a$ MF.
The lower BMD for lac $Z$ mutants is likely a result of the fact that lacZ is a multi-copy silent transgene (Shwed et al. 2010), whereas Pig- $a$ is an active, single copy endogenous gene (Phonethepswath et al. 2008). As such, lacZ transgene DNA is not subject to transcription-coupled repair (Lambert et al. 2005), resulting in a higher MF for a given dose (i.e., lower BMD) in comparison with an endogenous gene like Pig- $a$. Finally, MN are the result of a relatively narrow range of damage types (i.e., double strand breaks or whole chromosome loss) (Fenech et al. 2011), in comparison with point mutations that can accrue via a range of processes (e.g., base-pair substitutions, frame-shifts, deletions) (Lambert et al. 2005). Therefore, it is logical that a higher BMD would be observed for the $\mathrm{MN}$ endpoint than for the mutant endpoints, as we see here.

Although the aforementioned approach, which orders PoD across a series of sequential endpoints, is mechanistically appealing, we contend that it is inappropriate to directly compare BMDs across endpoints with different dynamic ranges of inducible responses (Fig. 5b). As specified in Slob (2017) endpoints with very large inducible ranges (i.e., many fold changes between control response and maximum inducible response) can be expected to yield very low BMD values as it requires very little effort to move the response above background to the BMR. This is especially apparent when comparing an endpoint with a relatively high theoretical maximum and very low detection limit (e.g., DNA adducts) to an endpoint such as \% MN. For the $\mathrm{MN}$ endpoint, the maximum response generally observed is ten- to 20-fold above background (Fig. 5b); in contrast, the observed maximum responses for the DNA adduct and lac Z mutant endpoints are 100- to 1000 -fold above background. This difference alone, regardless of the endpoints' sequential involvement in the determination of the adverse outcome, will contribute to a BMD series, for a set BMR, whereby adduct frequency is lowest, followed by mutation and chromosomal damage. The problem is further illustrated by consideration of the cancer endpoint, which is highly constrained with respect to maximum response, as the data are quantal (i.e., animals are tumor bearing or not). Therefore, at a BMR of $100,100 \%$ of the animals are tumor bearing, and thus it is not possible to have an effect size $>100 \%$. However, for continuous endpoints, a BMR of 100 simply reflects a two-fold doubling of control, which is, in comparison, a small, and relatively easily achieved effect size (Sander et al. 2005). A $10 \%$ increase in the incidence of cancer may be of concern, but, in contrast, a 10\% increase in adduct frequency may not constitute a significant disease-related change given the relative ease with which the latter endpoint can be moved away from the background. The approach presented by Slob (2017) to correct for cross-endpoint differences in theoretical maximum, will be applied to this and other genetic toxicity datasets in a forthcoming manuscript. 
Recent works by Soeteman-Hernández et al. employed the BMD approach to examine empirical relationships between several genetic toxicity and carcinogenicity endpoints (Hernández et al. 2011; Soeteman-Hernandez et al. 2015, 2016). However, there is a paucity of data examining quantitative relationships between DNA damage sensitivity (i.e., adduct sensitivity) and mutagenic sensitivity. In our study, when examining the relationship between DNA adducts and lac $Z$ mutants, we were only able to see a crosstissue relationship when the comparison was based on the BMD metric. This is the first demonstration of an empirical relationship between DNA adduct induction and mutation induction across several tissues. For $\mathrm{BaP}$, the results suggest a consistent, proportional conversion of adducts to mutations across tissues. DNA adduct frequency is a biomarker of exposure, whereas mutations and chromosomal damage are biomarkers of effect and, therefore, DNA adduct data are currently used in more of a qualitative manner to establish exposure and genotoxic potential of a compound (Sander et al. 2005). Additional research will be required to demonstrate whether proportionality between DNA adducts and mutations exist for other chemicals, but if this is confirmed, it may enable us to reliably use DNA adduct data in a more quantitative manner. This would be advantageous since DNA adduct frequency is much more readily assessed across tissues, and does not require the use of transgenic rodents.

Finally, it is important to note that this novel analysis approach need not be restricted to newly generated data such as those presented here. Analysis of published data, such as that previously presented by our group (Wills et al. 2016a, b), can permit the determination of potency or sensitivity rankings across compounds, tissues, cell types, and/or exposure regimens. The results of such analyses can reduce the necessity of additional studies, thus contributing to an overall reduction in animal use without sacrificing the precision of metrics used for human health risk assessment.

\section{Conclusions}

We documented BaP-induced genetic damage across all endpoints and tissues examined, even at very low doses (e.g., $0.2 \mathrm{mg} / \mathrm{kg} \mathrm{BW/day} \mathrm{for} \mathrm{spleen} \mathrm{adducts).} \mathrm{By} \mathrm{ranking}$ BMD CIs across tissues for a given endpoint, we observed that sensitivity varied significantly across tissues in regards to induced lacZ MF, and the differences were more pronounced in comparison with the DNA adduct endpoint. We were unable to observe cell population-specific sensitivity differences for Pig- $a$ MF and MN frequency endpoints. We demonstrated that the cross-tissue BMD trend was similar for both DNA adducts and lacZ mutants, and that this trend is consistent with tissue-specific differences in metabolism, proliferation, and repair. Moreover, we showed quantitative evidence that cross-tissue $\mathrm{BMD}_{100} \mathrm{~S}$ for DNA adduct induction are proportional to $\mathrm{BMD}_{100} \mathrm{~s}$ for lac $Z$ mutant induction, illustrating that the tissue-specific conversion of adducts to mutations is likely consistent, and that this empirical dependency is consistent across the seven tissues examined. Finally, our cross-endpoint comparisons of $\mathrm{BMD}_{100}$ values raised questions regarding the validity of comparisons based on a fixed BMR value. Cross-endpoint comparisons of BMD metrics using a fixed BMR have become unfortunately common, but this work and the earlier work of Slob (2017) indicate that, for comparisons to be meaningful, BMR values must be scaled according to endpoint-specific theoretical maxima. Overall, the BMD-approach employed herein permitted robust comparisons of responses across tissues and endpoints, and the information obtained adds valuable information to our mechanistic understanding of how BaP induces an array of genetic damage across several tissues. BMD rankings within an endpoint, and empirical comparisons across endpoints, contribute to an improved understanding of tissue-specific, chemically induced genetic damage, and this knowledge can provide a foundation for the selection of tissues, endpoints and BMRs for use in human health risk assessments. To enhance current understanding regarding the tissue-specific fixation of chemically induced genetic damage, future work should continue to examine the crosstissue relationships between chemically induced mutations and/or chromosomal damage and induced DNA damage.

Acknowledgements This project was funded by the Chemicals Management Plan and Health Canada intramural funding, as well as the Natural Sciences and Engineering Research Council of Canada. Volker M. Arlt was supported by Cancer Research UK (Grant C313/A14329), the Wellcome Trust (Grants 101126/Z/13/Z and 101126/B/13/Z), the Natural Environmental Research Council (Grant NE/L005782/1) and is a member of the Wellcome Trust funded COMSIG (Causes of Mutational SIGnatures) consortium. Stephen D. Dertinger was supported by the NIH-NIEHS (Grant R44ES021973). We are grateful to Cristina Aroche, Dorothy Krolak, Matthew Guo, and Elizabeth Richardson for technical assistance, to Dr. Martha Navarro, Julie Todd, Kevin Kittle, John Gingerich, Lynda Soper, Julie Cox, Dr. Jason O'Brien, and Taryn White for assistance with the animal study and necropsy, and to Dr. Carole Yauk, Dr. Nikolai Chepelev, and two anonymous reviewers for their critical review of the manuscript and insightful comments.

\section{Compliance with ethical standards}

Conflict of interest S. D. D. is an employee of Litron Laboratories. Litron holds patents covering flow cytometric methods for scoring micronucleated reticulocytes and sells kits based on this technology (In Vivo MicroFlow ${ }^{\circledR}$ ). Litron holds patents covering flow cytometric methods for scoring GPI anchor-deficient erythrocytes and sells kits based on this technology (In Vivo MutaFlow ${ }^{\circledR}$ ).

Open Access This article is distributed under the terms of the Creative Commons Attribution 4.0 International License (http://creativecommons.org/licenses/by/4.0/), which permits unrestricted use, distribution, and reproduction in any medium, provided you give appropriate 
credit to the original author(s) and the source, provide a link to the Creative Commons license, and indicate if changes were made.

\section{References}

Alexandrov LB, Ju YS, Haase K, Van Loo P, Martincorena I, NikZainal S et al (2016) Mutational signatures associated with tobacco smoking in human cancer. Science 354(6312):618-622

Becker K, Thomas AD, Kaina B (2014) Does increase in DNA repair allow "Tolerance-to-Insult" in chemical carcinogenesis? Skin tumor experiments with MGMT-overexpressing mice. Environ Mol Mutagen 55(2):145-150

Bemis JC, Wills JW, Bryce SM, Torous DK, Dertinger SD, Slob W (2016) Comparison of in vitro and in vivo clastogenic potency based on benchmark dose analysis of flow cytometric micronucleus data. Mutagenesis 31(3):277-285. doi:10.1093/mutage/ gev041

Bi X, Slater DM, Ohmori H, Vaziri C (2005) DNA polymerase kappa is specifically required for recovery from the benzo[a]pyrenedihydrodiol epoxide (BPDE)-induced S-phase checkpoint. J Biol Chem 280(23):22343-22355

Blanton RH, Lyte M, Myers MJ, Bick PH (1986) Immunomodulation by polyaromatic hydrocarbons in mice and murine cells. Cancer Res 46(6):2735-2739

Choudhary D, Jansson I, Schenkman JB, Sarfarazi M, Stoilov I (2003) Comparative expression profiling of 40 mouse cytochrome $\mathrm{P} 450$ genes in embryonic and adult tissues. Arch Biochem Biophys 414(1):91-100

Crump KS (1984) A new method for determining allowable daily intakes. Toxicol Sci 4(5):854-871

De Jong WH, Kroese ED, Vos JG, Van Loveren H (1999) Detection of immunotoxicity of benzo[a]pyrene in a subacute toxicity study after oral exposure in rats. Toxicol Sci 50(2):214-220

Dean JH, Luster MI, Boorman GA, Lauer LD, Leubke RW, Lawson L (1983) Selective immunosuppression resulting from exposure to the carcinogenic congener of benzopyrene in $\mathrm{B} 6 \mathrm{C} 3 \mathrm{~F} 1$ mice. Clin Exp Immunol 52(1):199-206

Dertinger SD, Camphausen K, Macgregor JT, Bishop ME, Torous DK, Avlasevich S et al (2004) Three-color labeling method for flow cytometric measurement of cytogenetic damage in rodent and human blood. Environ Mol Mutagen 44(5):427-435. doi:10.1002/ em. 20075

Dertinger SD, Bryce SM, Phonethepswath S, Avlasevich SL (2011) When pigs fly: immunomagnetic separation facilitates rapid determination of pig-a mutant frequency by flow cytometric analysis. Mutat Res 721(2):163-170. doi:10.1016/j.mrgentox.2011.01.009

Douglas GR, Gingerich JD, Gossen JA, Bartlett SA (1994) Sequence spectra of spontaneous lacZ gene mutations in transgenic mouse somatic and germline tissues. Mutagenesis 9(5):451-458

EFSA (2009) Guidance of the scientific committee on a request from EfSA on the use of benchmark dose approach in risk assessment. european food safety authority. EFSA J 1150:1-72

Eldridge SR, Goldsworthy SM (1996) Cell proliferation rates in common cancer target tissues of B6C3F1 mice and F344 rats: Effects of age, gender, and choice of marker. Toxicol Sci 32(2):159-167

Erickson RP (2010) Somatic gene mutation and human disease other than cancer: an update. Mutat Res Rev Mutat Res 705(2):96-106

Fearon ER (1997) Human cancer syndromes: clues to the origin and nature of cancer. Science 278(5340):1043-1050

Fenech M, Kirsch-Volders M, Natarajan AT, Surralles J, Crott JW, Parry J et al (2011) Molecular mechanisms of micronucleus, nucleoplasmic bridge and nuclear bud formation in mammalian and human cells. Mutagenesis 26(1):125-132. doi:10.1093/ mutage/geq052
Fowler PA, Dora NJ, McFerran H, Amezaga MR, Miller DW, Lea RG et al (2008) In utero exposure to low doses of environmental pollutants disrupts fetal ovarian development in sheep. Mol Hum Reprod 14(5):269-280. doi:10.1093/molehr/gan020

Fukushima S, Gi M, Kakehashi A, Wanibuchi H, Matsumoto M (2016) Qualitative and quantitative approaches in the dose-response assessment of genotoxic carcinogens. Mutagenesis 31(3):341346. doi:10.1093/mutage/gev049

Ginsberg GL, Atherholt TB (1989) Transport of DNA-adducting metabolites in mouse serum following benzo[a]pyrene administration. Carcinogenesis 10(4):673-679

Ginsberg GL, Atherholt TB (1990) DNA adduct formation in mouse tissues in relation to serum levels of benzo(a)pyrene-diol-epoxide after injection of benzo(a)pyrene or the diol-epoxide. Cancer Res 50(4):1189-1194

Ginsberg GL, Atherholt TB, Butler GH (1989) Benzo[a] pyreneinduced immunotoxicity: Comparison to DNA adduct formation in vivo, in cultured splenocytes, and in microsomal systems. J Toxicol Environ Health Part A Curr Issues 28(2):205-220

Gollapudi BB, Johnson GE, Hernandez LG, Pottenger LH, Dearfield KL, Jeffrey AM et al (2013) Quantitative approaches for assessing dose-response relationships in genetic toxicology studies. Environ Mol Mutagen 54(1):8-18. doi:10.1002/em.21727

Gossen JA, de Leeuw WJ, Tan CH, Zwarthoff EC, Berends F, Lohman $\mathrm{PH}$ et al (1989) Efficient rescue of integrated shuttle vectors from transgenic mice: a model for studying mutations in vivo. Proc Natl Acad Sci USA 86(20):7971-7975

Gossen JA, Molijn AC, Douglas GR, Vijg J (1992) Application of galactose-sensitive $E$. coli strains as selective hosts for $\mathrm{LacZ}^{-}$ plasmids. Nucleic Acids Res 20(12):3254

Hakura A, Tsutsui Y, Sonoda J, Kai J, Imade T, Shimada M et al (1998) Comparison between in vivo mutagenicity and carcinogenicity in multiple organs by benzo[a] pyrene in the lacZ transgenic mouse (muta ${ }^{\mathrm{TM}}$ mouse). Mutat Res Fund Mol Mech Mutag 398(1):123-130

Hanahan D, Weinberg RA (2011) Hallmarks of cancer: the next generation. Cell 144(5):646-674

Health Canada (1994) Canadian environmental protection act: human health risk assessment for priority substances. Canada Communication Group, Ottawa, Canada. ISBN: 0-662-22126-5

Heidel SM, Czuprynski CJ, Jefcoate CR (1998) Bone marrow stromal cells constitutively express high levels of cytochrome P4501B1 that metabolize 7,12-dimethylbenz[a]anthracene. Mol Pharmacol 54(6):1000-1006

Hemminki K (1993) DNA adducts, mutations and cancer. Carcinogenesis 14(10):2007-2012

Hemminki K, Koskinen M, Rajaniemi H, Zhao C (2000) DNA adducts, mutations, and cancer 2000. Regul Toxicol Pharmacol 32(3):264-275

Hernández LG, Slob W, van Steeg H, van Benthem J (2011) Can carcinogenic potency be predicted from in vivo genotoxicity data? a meta-analysis of historical data. Environ Mol Mutagen 52(7):518-528

IARC (2010a) Chemical agents and related occupations: A review of human carcinogens. IARC Monogr Eval Carcinog Risks Hum 100F:1-628

IARC (2010b) Some non-heterocyclic polycyclic aromatic hydrocarbons and some related exposures. IARC Monogr Eval Carcinog Risks Hum 92:1-853

IARC (2012) Chemical agents and related occupations. international agency for research on cancer. IARC Monogr Eval Carcinog Risks Hum 100F:111-144

IARC (2014) Diesel and gasoline engine exhausts and some nitroarenes. IARC Monogr Eval Carcinog Risks Hum 105:1-703

Johnson GE, Soeteman-Hernandez LG, Gollapudi BB, Bodger OG, Dearfield KL, Heflich RH et al (2014) Derivation of point of 
departure (PoD) estimates in genetic toxicology studies and their potential applications in risk assessment. Environ Mol Mutagen 55(8):609-623. doi:10.1002/em.21870

Krais AM, Speksnijder EN, Melis JP, Indra R, Moserova M, Godschalk RW et al (2016) The impact of p53 on DNA damage and metabolic activation of the environmental carcinogen benzo[a] pyrene: Effects in Trp53 (++/ ), Trp53 (+/-) and Trp53 (-/-) mice. Arch Toxicol 90(4):839-851

Kroese E, Muller J, Mohn G, Dortant P, Wester P. 2002. Tumorigenic effects in wistar rats orally administered benzo[a] pyrene for two years (gavage studies). implications for human cancer risks associated with oral exposure to polycyclic aromatic hydrocarbons. 658603010:Rijksinstituut voor Volksgezondheid en Milieu RIVM

Kucab JE, van Steeg H, Luijten M, Schmeiser HH, White PA, Phillips DH et al (2015) TP53 mutations induced by BPDE in xpa-WT and xpa-null human TP53 knock-in (hupki) mouse embryo fibroblasts. Mutat Res Fund Mol Mech Mutag 773:48-62

Kucab JE, Zwart EP, van Steeg H, Luijten M, Schmeiser HH, Phillips DH et al (2016) TP53 and lacZ mutagenesis induced by 3 -nitrobenzanthrone in xpa-deficient human TP53 knock-in mouse embryo fibroblasts. DNA Repair 39:21-33

Labash C, Avlasevich SL, Carlson K, Berg A, Torous DK, Bryce $\mathrm{SM}$ et al (2016) Mouse pig-a and micronucleus assays respond to $N$-ethyl- $N$-nitrosourea, benzo[a]pyrene, and ethyl carbamate, but not pyrene or methyl carbamate. Environ Mol Mutagen 57(1):28-40

Lambert IB, Singer TM, Boucher SE, Douglas GR (2005) Detailed review of transgenic rodent mutation assays. Mutat Res $590(1-3): 1-280$

Lambert IB, Singer TM, Boucher SE, Douglas GR (2009) Detailed review paper on transgenic rodent mutation assays. OECD series on Testing and Assessment 103. http://www.oecd.org/ officialdocuments/publicdisplaydocumentpdf/?cote=env/jm/ mono(2009) $7 \&$ doclanguage $=$ en. Accessed 30 Oct 2017

Lemieux CL, Douglas GR, Gingerich J, Phonethepswath S, Torous DK, Dertinger SD et al (2011) Simultaneous measurement of benzo[a] pyrene-induced pig-a and lacZ mutations, micronuclei and DNA adducts in muta mouse. Environ Mol Mutagen 52(9):756-765. doi: $10.1002 / \mathrm{em} .20688$

Long AS, Lemieux CL, Arlt VM, White PA (2016) Tissue-specific in vivo genetic toxicity of nine polycyclic aromatic hydrocarbons assessed using the Muta ${ }^{\mathrm{TM} M o u s e}$ transgenic rodent assay. Toxicol Appl Pharmacol 290(1):31-42

MacGregor JT, Frötschl R, White PA, Crump KS, Eastmond DA, Fukushima $S$ et al (2015a) IWGT report on quantitative approaches to genotoxicity risk assessment I. methods and metrics for defining exposure-response relationships and points of departure (PoDs). Mutat Res Genet Toxicol Environ Mutag 783:55-65

MacGregor JT, Frotschl R, White PA, Crump KS, Eastmond DA, Fukushima $S$ et al (2015b) IWGT report on quantitative approaches to genotoxicity risk assessment II. use of point-of-departure (PoD) metrics in defining acceptable exposure limits and assessing human risk. Mutat Res Genet Toxicol Environ Mutagen 783:6678. doi:10.1016/j.mrgentox.2014.10.008

Meek ME, Palermo CM, Bachman AN, North CM, Jeffrey Lewis R (2014) Mode of action human relevance (species concordance) framework: evolution of the bradford hill considerations and comparative analysis of weight of evidence. J Appl Toxicol 34(6):595606. doi:10.1002/jat.2984

Meier MJ, O’Brien JM, Beal MA, Allan B, Yauk CL, Marchetti F (2016) In utero exposure to benzo[a]pyrene increases mutation burden in the soma and sperm of adult mice. Environ Health Perspect. doi:10.1289/EHP211

Merritt AJ, Allen TD, Potten CS, Hickman JA (1997) Apoptosis in small intestinal epithelial from p53-null mice: evidence for a delayed, p53-independent G2/M-associated cell death after gamma-irradiation. Oncogene 14(23):2759-2766. doi:10.1038/ sj.onc. 1201126

Miller KP, Ramos KS (2001) Impact of cellular metabolism on the biological effects of benzo[a]pyrene and related hydrocarbons. Drug Metab Rev 33(1):1-35

Mocarelli P, Gerthoux PM, Needham LL, Patterson DG Jr, Limonta G, Falbo R et al (2011) Perinatal exposure to low doses of dioxin can permanently impair human semen quality. Environ Health Perspect 119(5):713

Modgil S, Lahiri DK, Sharma VL, Anand A (2014) Role of early life exposure and environment on neurodegeneration: implications on brain disorders. Transl Neurodegener 3(1):1

Moffat I, Chepelev NL, Labib S, Bourdon-Lacombe J, Kuo B, Buick JK et al (2015) Comparison of toxicogenomics and traditional approaches to inform mode of action and points of departure in human health risk assessment of benzo[a]pyrene in drinking water. Crit Rev Toxicol 45(1):1-43

Muskhelishvili L, Latendresse JR, Kodell RL, Henderson EB (2003) Evaluation of cell proliferation in rat tissues with BrdU, PCNA, ki-67(MIB-5) immunohistochemistry and in situ hybridization for histone mRNA. J Histochem Cytochem 51(12):1681-1688

OECD (2013) Test no. 488: Transgenic rodent somatic and germ cell gene mutation assays. OECD test guideline. doi:10.1787/9789264203907-en

Ozkan L, Ozuysal S, Egeli U, Adim SB, Tunca B, Aydemir N et al (2001) Effects of taxol plus radiation on the apoptotic and mitotic indices of mouse intestinal crypt cells. J Cancer Res Clin Oncol 127(7):433-438

Penning TM (2014) Human aldo-keto reductases and the metabolic activation of polycyclic aromatic hydrocarbons. Chem Res Toxicol 27(11):1901-1917. doi:10.1021/tx500298n

Perera F, Phillips DH, Wang Y, Roen E, Herbstman J, Rauh V et al (2015) Prenatal exposure to polycyclic aromatic hydrocarbons/aromatics, BDNF and child development. Environ Res 142:602-608

Phillips DH, Arlt VM (2014) (3)(2)P-postlabeling analysis of DNA adducts. Methods Mol Biol 1105:127-138. doi:10.1007/978-1-62703-739-6_10

Phillips DH, Castegnaro M (1999) Standardization and validation of DNA adduct postlabelling methods: report of interlaboratory trials and production of recommended protocols. Mutagenesis 14(3):301-315

Phonethepswath S, Bryce SM, Bemis JC, Dertinger SD (2008) Erythrocyte-based pig-a gene mutation assay: demonstration of crossspecies potential. Mutat Res 657(2):122-126. doi:10.1016/j. mrgentox.2008.08.011

Pottenger LH, Gollapudi BB (2010) Genotoxicity testing: moving beyond qualitative "screen and bin" approach towards characterization of dose-response and thresholds. Environ Mol Mutagen 51(8-9):792-799. doi:10.1002/em.20612

Radulescu S, Ridgway RA, Appleton P, Kroboth K, Patel S, Woodgett $\mathrm{J}$ et al (2010) Defining the role of APC in the mitotic spindle checkpoint in vivo: APC-deficient cells are resistant to taxol. Oncogene 29(49):6418-6427. doi:10.1038/onc.2010.373

Ramesh A, Walker SA, Hood DB, Guillen MD, Schneider K, Weyand EH (2004) Bioavailability and risk assessment of orally ingested polycyclic aromatic hydrocarbons. Int J Toxicol 23(5):301-333

Renaud HJ, Cui JY, Khan M, Klaassen CD (2011) Tissue distribution and gender-divergent expression of 78 cytochrome P450 mRNAs in mice. Toxicol Sci 124(2):261-277

Sander M, Cadet J, Casciano DA, Galloway SM, Marnett LJ, Novak RF et al (2005) Proceedings of a workshop on DNA adducts: biological significance and applications to risk assessment washington, DC, April 13-14, 2004. Toxicol Appl Pharmacol 208(1):1-20 
Shami SG, Evans MJ (1992) Kinetics of pulmonary cells. In: Parent RA (ed) Treatise on pulmonary toxicology. CRC Press, Boca Raton, pp 145-155

Shimada T, Fujii-Kuriyama Y (2004) Metabolic activation of polycyclic aromatic hydrocarbons to carcinogens by cytochromes $\mathrm{P} 450$ 1A1 and 1B1. Cancer Sci 95(1):1-6

Shimada T, Inoue K, Suzuki Y, Kawai T, Azuma E, Nakajima T et al (2002) Arylhydrocarbon receptor-dependent induction of liver and lung cytochromes P450 1A1, 1A2, and 1B1 by polycyclic aromatic hydrocarbons and polychlorinated biphenyls in genetically engineered C57BL/6 J mice. Carcinogenesis 23(7):1199-1207

Shwed PS, Crosthwait J, Douglas GR, Seligy VL (2010) Characterisation of MutaMouse lambdagt10-lacZ transgene: evidence for in vivo rearrangements. Mutagenesis 25(6):609-616. doi:10.1093/ mutage/geq048

Slob W (2002) Dose-response modeling of continuous endpoints. Toxicol Sci 66(2):298-312

Slob W (2017) A general theory of effect size, and its consequences for defining the benchmark response (BMR) for continuous endpoints. Crit Rev Toxicol 47(4):342-351

Snipes RL (1967) Cellular dynamics in the jejunum of essential fatty acid deficient mice. Anat Rec 159(4):421-429. doi:10.1002/ ar.1091590411

Soeteman-Hernandez LG, Fellows MD, Johnson GE, Slob W (2015) Correlation of in vivo versus in vitro benchmark doses (BMDs) derived from micronucleus test data: a proof of concept study. Toxicol Sci 148(2):355-367. doi:10.1093/toxsci/kfv189

Soeteman-Hernandez LG, Johnson GE, Slob W (2016) Estimating the carcinogenic potency of chemicals from the in vivo micronucleus test. Mutagenesis 31(3):347-358

Speit G, Autrup H, Crebelli R, Henderson L, Kirsch-Volders M, Madle $S$ et al (2000) Thresholds in genetic toxicology-concluding remarks. Mutat Res 464(1):149-153

Thomas RS, Allen BC, Nong A, Yang L, Bermudez E, Clewell HJ 3rd et al (2007) A method to integrate benchmark dose estimates with genomic data to assess the functional effects of chemical exposure. Toxicol Sci 98(1):240-248

Thomas AD, Jenkins GJ, Kaina B, Bodger OG, Tomaszowski KH, Lewis PD et al (2013) Influence of DNA repair on nonlinear doseresponses for mutation. Toxicol Sci 132(1):87-95. doi:10.1093/ toxsci/kfs341

Thomas AD, Fahrer J, Johnson GE, Kaina B (2015) Theoretical considerations for thresholds in chemical carcinogenesis. Mutat Res Rev Mutat Res 765:56-67

Uno S, Dalton TP, Dragin N, Curran CP, Derkenne S, Miller ML et al (2006) Oral benzo[a]pyrene in Cyp1 knockout mouse lines: CYP1A1 important in detoxication, CYP1B1 metabolism required for immune damage independent of total-body burden and clearance rate. Mol Pharmacol 69(4):1103-1114
Van Oostrom CT, Boeve M, van den Berg J, De Vries A, Dolle ME, Beems RB et al (1999) Effect of heterozygous loss of p53 on benzo[a]pyrene-induced mutations and tumors in DNA repairdeficient XPA mice. Environ Mol Mutagen 34(2-3):124-130

Vijg J, Douglas G (1996) Bacteriophage lambda and plasmid lacZ transgenic mice for studying mutations in vivo. In: Pfeifer G (ed) Technologies for detection of DNA damage and mutations. Plenum Press, New York, pp 391-410

Wang Y, Arlt VM, Roufosse CA, McKim KL, Myers MB, Phillips DH et al (2012) ACB-PCR measurement of h-ras codon $61 \mathrm{CAA} \rightarrow$ CTA mutation provides an early indication of aristolochic acid I carcinogenic effect in tumor target tissues. Environ Mol Mutagen 53(7):495-504

White KJ, Kawabata T, Ladics G (1994) Mechanisms of polycyclic aromatic hydrocarbon immunotoxicity. In: Dean JH, Luster MI, Munson AE, Kimber I (eds) Immunotoxicology and immunopharmacology. Raven Press Ltd., New York, pp 123-142

White PA, Douglas GR, Phillips DH, Arlt VM (2017) Quantitative relationships between lac Z mutant frequency and DNA adduct frequency in Muta ${ }^{\mathrm{TM}}$ Mouse tissues and cultured cells exposed to 3-nitrobenzanthrone. Mutagenesis 32(2):299-312

Wills JW, Johnson GE, Doak SH, Soeteman-Hernandez LG, Slob W, White PA (2016a) Empirical analysis of BMD metrics in genetic toxicology part I: in vitro analyses to provide robust potency rankings and support MOA determinations. Mutagenesis 31(3):255263. doi:10.1093/mutage/gev085

Wills JW, Long AS, Johnson GE, Bemis JC, Dertinger SD, Slob W et al (2016b) Empirical analysis of BMD metrics in genetic toxicology part II: in vivo potency comparisons to promote reductions in the use of experimental animals for genetic toxicity assessment. Mutagenesis 31(3):265-275. doi:10.1093/mutage/gew009

Wohak LE, Krais AM, Kucab JE, Stertmann J, Øvrebø S, Seidel A et al (2016) Carcinogenic polycyclic aromatic hydrocarbons induce CYP1A1 in human cells via a p53-dependent mechanism. Arch Toxicol 90(2):291-304

Wu S, Powers S, Zhu W, Hannun YA (2016) Substantial contribution of extrinsic risk factors to cancer development. Nature 529(7584):43-47

Xue W, Warshawsky D (2005) Metabolic activation of polycyclic and heterocyclic aromatic hydrocarbons and DNA damage: a review. Toxicol Appl Pharmacol 206(1):73-93

Zair ZM, Jenkins GJ, Doak SH, Singh R, Brown K, Johnson GE (2011) $N$-methylpurine DNA glycosylase plays a pivotal role in the threshold response of ethyl methanesulfonate-induced chromosome damage. Toxicol Sci 119(2):346-358. doi:10.1093/toxsci/ kfq341 